Please do not remove this page

RMIT

UNIVERSITY

\title{
Characterisation of bulk water samples from copper pipes undergoing microbially influenced corrosion by diagnostic metabolomic profiling
}

Beale, David; Dunn, Michael; Morrison, Paul; Porter, Nichola; Marlow, David

https://researchrepository.rmit.edu.au/esploro/outputs/9921858367701341/filesAndLinks?institution=61RMIT_INST\&index=null

Beale, D., Dunn, M., Morrison, P., Porter, N., \& Marlow, D. (2012). Characterisation of bulk water samples from copper pipes undergoing microbially influenced corrosion by diagnostic metabolomic profiling.

Corrosion Science, 55, 272-279. https://doi.org/10.1016/j.corsci.2011.10.026

Published Version: https://doi.org/10.1016/j.corsci.2011.10.026

Repository homepage: https://researchrepository.rmit.edu.au

(c) 2011 Published by Elsevier Ltd.

Downloaded On 2023/04/26 17:01:27 +1000

Please do not remove this page 

profiling', Corrosion Science, vol. 55, pp. 272-279.

\title{
Characterization of Bulk Water Samples from Copper Pipes Undergoing Microbially Influenced Corrosion by Diagnostic Metabolomic Profiling
}

\author{
David J Beale ${ }^{1^{*}}$, Michael S. Dunn ${ }^{2 \& 3}$, Paul D. Morrison ${ }^{3}$, Nichola A. Porter $^{3}$ \\ \& David R. Marlow ${ }^{1}$
}

\begin{abstract}
${ }^{1}$ Commonwealth Scientific and Industrial Research Organisation (CSIRO), Land and Water, P.O. Box 56, Highett 3190, VIC Australia.

${ }^{2}$ Ensign Laboratories, P.O Box 268, Mulgrave 3170, VIC Australia.

${ }^{3}$ Royal Melbourne Institute of Technology (RMIT University), School of Applied Sciences, G.P.O. Box 2476, Melbourne 3001, VIC Australia.
\end{abstract}

\begin{abstract}
:
This paper presents the application of metabolomic techniques to determine the presence of microbial influenced corrosion (MIC). In a previous study, the extracellular metabolites expressed from pipe biofilm was identified by analysing the passing water. This investigation extends this work by successfully applying a chemometric statistical analysis to the extracellular metabolomic profile of a number of water samples to identify critical metabolomic biomarkers. The chemometric analysis was able to differentiate samples due to a reduction of carboxylic acids in samples exposed to bacteria believed to cause MIC.
\end{abstract}

Keywords: Copper, Microbiological corrosion.

\section{Abbreviations:}

* Corresponding Author: David J. Beale (david.beale@csiro.au). CSIRO Land and Water, PO Box 56, Highett 3190, Australia. Tel: +61 39252 6602, Fax: +61 392526244. 
- MIC: microbial influenced corrosion

- BGW: blue green water

- EPS: extracellular polymeric substances

- SRB: sulfur reducing bacteria

- GC/MS: gas chromatography mass spectroscopy

- PLS-DA: partial least squares data analysis

\section{Introduction}

Copper is a common material used in residential, commercial and industrial plumbing systems because of its robustness and malleability [1]. Although often assumed to have inherent anti-microbial properties, it is however, not unusual for the biofilm found on copper surfaces to influence electrochemical processes that lead to material degradation (corrosion) [2]. For the management of residential, private or government water reticulation plumbing systems, the occurrence of MIC on the inner surface of metal piping infrastructure poses a serious and costly problem [3]. It is estimated that copper corrosion costs home-owners millions of dollars each year in terms of repair and replacement of failing assets (i.e., replacing pitted pipes, water heaters and other appliances affected by copper corrosion product and particulates) and mitigating the ill-health effects which result from drinking water contaminated with copper in the USA alone [4].

For copper piping in particular, MIC can result in a condition known as blue-green water (BGW), where the deterioration of the pipe surface has led to an increase of particulate corrosion products in the water. In terms of quality assurance and control, an outbreak of BGW will almost certainly cause the water to fail the recommended drinking water health guidelines [5].

Due to the high costs associated with repairing or replacing copper assets damaged by MIC, the issue has become a significant area of scientific research. In particular, the identification 
and characterization of the microbial organisms that cause MIC and the specific conditions under which MIC occurs has become a major focus $[6,7]$. While it is acknowledged that the reasons why the MIC phenomenon occurs in some places and not others are yet to be fully understood, recent research has indicated that the quality of water $(\mathrm{pH}$, hardness, and nutrient content) and the grade of copper used in the construction of the pipe are contributing factors [6-12].

One way to better understand and manage this problem is to develop a methodology for identifying whether corrosion is microbially influenced before implementing strategies to ameliorate the problem. As such, the focus of this research is to develop a method for the early identification of biofilms that are susceptible to MIC in water pipe infrastructure using passive analytical techniques. In an earlier study, it was found that a chemical profile of the extracellular metabolites from a microbial biofilm attached to household reticulation piping could be achieved by analysing the passing water [13]. This paper extends the work by considering the possibility of using metabolomic techniques for infrastructure monitoring, and as such, is structured in the following way: firstly, a summary of the pipe-biofilm-fluid interface is presented, focusing on metabolite mass transfer characteristics. This is followed by an articulation of the potential of a metabolomic approach for assessing and monitoring biofilm activity.

\subsection{Biofilms and metabolites}

Biofilms in water supply networks typically comprise a consortium of bacteria within a EPS matrix. Metabolite transfer in this biological network has been described as a system dominated by molecular diffusion and other more irregular transport processes (e.g. via pores and channels in the biofilm created by irregular stacking of cells) [14]. Metabolite mass transfer across biofilms on water supply infrastructure is primarily influenced by the type of flow in terms of the degree of turbulence, and the velocity of water flow within the system. For water supply networks, the flow of water is characterised as turbulent. Some regions in the network are considered to be operated under high, intermediate or low flow; in some 
cases, there may be regions or periods of stagnation, e.g. unused customer taps, valve voids etc. [15]. In such systems, eddy or turbulent diffusion occurs as a result of the irregular physical characteristics (cell stacking and irregular biofilm colonisation). This type of diffusion is said to occur in the region close to the water-biofilm interface, where the irregular biofilm surface results in increased friction which retards the flow thereby creating a diffusive boundary layer $[1,14,16]$. However, with increased flow, the thickness of the diffusive boundary layer decreases which results in an increase in the outward transfer of metabolites from the biofilm. To further complicate matters, the highly irregular EPS structure may contain pores or channels through which liquids can flow; this increases the rate of molecular diffusion [17]. As such, for pipes used for transporting water, metabolite transfer occurs between the biofilm and the passing water, and occurs by both molecular and eddy diffusion. All transportation process will be significantly increased by the flow velocity [17].

\subsection{The metabolome as an indicator of biofilm activity}

Common methods used to detect and monitor biofilms within the water supply network involve regular grab sampling of the bulk water and measuring physical, chemical and biological parameters. Procedures recommend that properties such as temperature, $\mathrm{pH}$, conductivity, and total dissolved salts be monitored at monthly intervals in addition to cultivating samples in order to characterise bacterial counts and identify organisms (NH\&MRC, 2004). The primary goal for this monitoring is to identify conditions which promote biofilm growth and observe changes in bacterial trends i.e., it is considered more important to identify changes in the bacterial-biofilm composition than to identify increased bacterial numbers $[14,18,19]$. While physical and chemical analysis can be done in-situ or quickly in a laboratory, bacterial cultivation investigations tend to be more time consuming.

A number of sophisticated analytical methodologies have been used to better understand the biofilm - pipe interface interactions; these include a range of microscopy techniques and surface chemistry analytic techniques (e.g. SEM, XRD, TOF-MS etc; see review by Beech 
[2]). Data from these techniques yield information that allows improved characterisation and understanding of the surface biochemical reactions between the metal and the biofilm. However, these techniques tend to be considered forensic type analysis in that they are undertaken after MIC is suspected of occurring.

An alternative approach, metabolomics, which is considered in this work, takes advantage of the concentration profile and the types of metabolites excreted from and consumed by the biofilm. The mass transfer of metabolites from the biofilm to the water enables the realistic consideration of metabolomic techniques for infrastructure monitoring. Metabolomics is described as the investigation of biological processes through the chemical compounds they consume (substrates) and the metabolites expelled, this has been coined the metabolome [20]. In order to develop a passive method for investigating biofilms (and in the context of corrosion, biofilms that are believed to cause $\mathrm{MIC}$ ), a metabolomic analysis targeting the extracellular metabolites released into the passing water via mass transfer processes is desired. In an earlier study it was found that a profile of the extracellular metabolites from a microbial biofilm attached to a copper pipe could be achieved by analysing the passing water using gas chromatography, and by using the chromatogram along with the mass spectrometric data, the samples could be used to differentiate biofilms from numerous samples [13].

It is therefore envisaged that for each stage of biofilm development, whether it be early attachment and growth, or oxidation/reduction phases, the type of metabolites expelled and substrates consumed will vary. Therefore, a metabolomic profile can be identified which is representative of the biofilm activity. In addition, through data mining and analysis of each profile, or chromatogram of metabolites, the type of biofilm activity can be inferred, and by extension an estimation of infrastructure corrosion likelihood could be made. 


\section{Methodology}

\subsection{Samples}

A series of water samples were collected from an accelerated laboratory corrosion trial for analysis (Table 1). Each sample was analysed for free copper by inductively coupled plasma atomic emission spectroscopy (ICP-AES) and any visible observation of BGW was noted. The metabolomic analysis included a combination of ultra violet visible spectroscopy (UVvis), three dimensional excitation emission matrix (3DEEM) fluorescence spectroscopy and derivatised gas chromatography mass spectroscopy (GC/MS). The spectrometric techniques provided an initial rapid screening of specific chemical classes that make up the metabolome of microbes, while the derivatised GC/MS provided confirmation of individual metabolites. All three analytical techniques are discussed in more detail below. 
Table 1: Summary of samples collected for extracellular metabolomic analysis.

\begin{tabular}{|c|c|c|c|}
\hline Sample & $\begin{array}{l}\text { Sample } \\
\text { Source }\end{array}$ & $\begin{array}{l}\text { Copper* }[\mathrm{Cu}] \\
\mathrm{mg} \mathrm{L}^{-1}\end{array}$ & Observations \\
\hline 1 & $\begin{array}{l}\text { Laboratory trial of } \\
\text { copper MIC }\end{array}$ & $15.4(105.4)$ & $\begin{array}{l}\text { Samples exhibiting BGW precipitate, } \\
\text { samples exposed to bacteria that are } \\
\text { believed to cause MIC in copper; } \\
\text { accelerated corrosion laboratory trial. }\end{array}$ \\
\hline 2 & $\begin{array}{l}\text { Laboratory trial of } \\
\text { copper MIC }\end{array}$ & $0.84(13.0)$ & $\begin{array}{l}\text { Sample of water exposed to bacteria } \\
\text { that are believed to cause MIC in } \\
\text { copper; accelerated corrosion } \\
\text { laboratory trial. }\end{array}$ \\
\hline 3 & $\begin{array}{l}\text { Laboratory trial of } \\
\text { copper MIC }\end{array}$ & $0.64(7.2)$ & $\begin{array}{l}\text { Sample of water exposed to bacteria } \\
\text { that are believed to cause MIC in } \\
\text { copper; accelerated corrosion } \\
\text { laboratory trial. }\end{array}$ \\
\hline 4 & $\begin{array}{l}\text { Laboratory trial of } \\
\text { copper MIC }\end{array}$ & $0.43(2.3)$ & $\begin{array}{l}\text { Sample of water exposed to bacteria } \\
\text { that are believed to cause MIC in } \\
\text { copper; accelerated corrosion } \\
\text { laboratory trial. }\end{array}$ \\
\hline 5 & $\begin{array}{l}\text { Laboratory trial of } \\
\text { copper MIC }\end{array}$ & $0.86(6.6)$ & $\begin{array}{l}\text { Sample of water exposed to bacteria } \\
\text { that are believed to cause MIC in } \\
\text { copper; accelerated corrosion } \\
\text { laboratory trial. }\end{array}$ \\
\hline 6 & $\begin{array}{l}\text { Laboratory trial of } \\
\text { copper MIC } \\
\text { (blank) }\end{array}$ & $0.21(0.3)$ & $\begin{array}{l}\text { Procedural blank; exposed to the same } \\
\text { conditions as the laboratory trial but not } \\
\text { seeded with BGW seed. }\end{array}$ \\
\hline 7 & $\begin{array}{l}\text { Laboratory trial of } \\
\text { copper MIC } \\
\text { (blank) }\end{array}$ & $0.30(0.4)$ & $\begin{array}{l}\text { Procedural blank; exposed to the same } \\
\text { conditions as the laboratory trial but not } \\
\text { seeded with BGW seed. }\end{array}$ \\
\hline 8 & $\begin{array}{l}\text { Reverse osmosis } \\
\text { filtration }\end{array}$ & $0.0(0.0)$ & $\begin{array}{l}\text { No visible signs of BGW; Analytical } \\
\text { method blank }\end{array}$ \\
\hline 9 & $\begin{array}{l}\text { Reverse osmosis } \\
\text { filtration }\end{array}$ & $0.0(0.0)$ & $\begin{array}{l}\text { No visible signs of BGW; Analytical } \\
\text { method blank }\end{array}$ \\
\hline 10 & BGW sample & $18.6(125.0)$ & Samples exhibiting BGW precipitate. \\
\hline
\end{tabular}

Samples 1 to 5 were taken from three identical laboratory experiments that attempted to mimic the copper MIC process by cultivating microbial growth on the surface of submerged copper. Samples 6 and 7 were taken from the same trial, but were not exposed to MIC bacteria; the experimental conditions and trial details are discussed below. Samples 8 and 9 are effectively analytical blanks and were obtained from a Milli-Q reverse osmosis water purification system. Sample 10 was a BGW sample from a residential tap. It should be noted, as per our preliminary study, the analysis of water samples from copper exposed to a single bacterium culture was not considered for this study [13]. The aim of this study was to profile 
the metabolites from a simulated BGW event caused by a consortium of bacteria. As such, the full metabolome can be realised.

\subsection{Laboratory Prepared Copper MIC}

Small copper tube samples (300 mm (I) x 90 mm (i.d.); $\mathrm{n}=5$ ) were cleaned in $1 \%$ nitric acid before rinsing with MilliQ water. Copper samples were then placed into $1 \mathrm{~L}$ Schott bottles filled with tap water; $\mathrm{pH}$ was adjusted to 9.5 with lime prior to autoclaving at $121^{\circ} \mathrm{C}$ for 2 hours. A BGW seed was then added aseptically and samples were stored at room temperature (ca. $21^{\circ} \mathrm{C}$ ) in the dark; $\mathrm{pH}$ and dissolved oxygen (DO) were maintained monthly by bubbling $0.2 \mu \mathrm{m}$ filtered $\mathrm{CO}_{2}$-free compressed air for 2 minutes (BOC; Dandenong, VIC, Australia). The BGW seed comprised a mixed bacteria culture from numerous known "bluegreen water" taps within CSIRO laboratories (Clayton, VIC, Australia) [6]. The bacterium in the culture were identified as: Sphingomonas sp., Caulobacter sp., Sphingomonas adheasiva, Acidovorax sp., Methylobacterium sp. and Desulfovibrio desulfuricans. In addition, a series of copper tubes were put aside and not exposed to the MIC bacterium; these samples were maintained in accordance to the method described above and constitute the control group in subsequent analysis.

\subsection{Ultra Violet- visible spectroscopy (UV-vis)}

Absorbance measurements were conducted on a Cary 300 UV-Vis spectrometer (Varian, USA) operating WinUV (Varian, USA). Absorbance was recorded over 190 - $700 \mathrm{~nm}$ with quartz cuvettes [13].

\subsection{Three Dimensional Excitation/Emission (3DEEM) Fluorescence Spectroscopy} As demonstrated previously [13], 3DEEM fluorescence spectroscopy was performed with a fluorescence spectrophotometer (Perkin Elmer, Model LS 50B) operating FL WinLab (Perkin Elmer, USA) with fused quartz cells. The 3DEEM spectroscopy was undertaken in order to screen the samples for fluorophores that indicate biological activity. The wavelengths studied 
ranged from 200 to $600 \mathrm{~nm}$ for excitation ( $5 \mathrm{~nm}$ bandwidth), and from 200 to $600 \mathrm{~nm}$ for emission (5 $\mathrm{nm}$ bandwidth).

\subsection{Inductively coupled plasma atomic emission spectroscopy (ICP-AES)}

All samples were analysed using a Varian Liberty Series II Axial ICP-AES system. A series of filtered (free copper) and digested (total copper) samples were prepared; filtered samples had been passed through a $0.45 \mu \mathrm{m}$ syringe filter (Bonnet, Australia). Prior to analysis the sample $\mathrm{pH}$ was adjusted with nitric acid $(6 \mathrm{M})$ to $\mathrm{pH} 2(1 \% \mathrm{v}: \mathrm{v})$.

\subsection{Metabolomic GC/MS Analysis}

Following the extraction process described below, the metabolites were removed from the original water samples and concentrated. The extracted metabolites were then chemically derivatised prior to being analysed by GC/MS (Agilent Model 6890/5973). Three derivitising reagents were investigated and compared for their ability to derivitise the entire range of metabolites found in the samples. Details of the sample preparation are given below.

\subsubsection{Liquid-liquid extraction}

A $100 \mu \mathrm{L}$ aliquot of methoxyamine hydrochloride (1 $\mathrm{mol} \mathrm{L}^{-1}$; Sigma-Aldrich, Australia) in MilliQ water was added to $5.0 \mathrm{~mL}$ of sample and placed in a microwave instrument (CEM MARS-5, Buckingham, UK) at $420 \mathrm{~W}$ for $90 \mathrm{~s}$. After cooling and saturating with solid sodium chloride, $50 \mu \mathrm{L}$ of hydrochloric acid $\left(6 \mathrm{~mol} \mathrm{~L}^{-1}\right)$ was added and then the solution was extracted with $5.0 \mathrm{~mL}$ of ethyl acetate for 5.0 minutes on a rotary mixer. The upper organic layer was separated by centrifugation (5.0 minutes @ 1,200 rpm), and then transferred to clean glass tubes containing $10 \mu \mathrm{L}$ of $25 \%$ ammonia to minimize evaporative losses of volatile organic acids. The samples were then dried completely under a stream of $\mathrm{N}_{2}$ at $60^{\circ} \mathrm{C}$ prior to derivatisation and solvent exchange [13]. 


\subsubsection{Sample derivatisation}

Three derivatisation reagents commonly used for GC analysis were tested in order to assess their suitability for MIC metabolomic analysis of copper pipes. These reagents were: trimethylsulphonium hydroxide (TMSH) for alkylation, N-methyl-bis(tri-fluoro-acetamide) (MBTFA) for acylation, and N-methyl-N-trimethyl-silyl-trifluoro-acetamide (MSTFA) for silylation.

$R$-methyl derivatives were formed by adding $100 \mu \mathrm{L} \mathrm{TMSH}$; trimethysilyl derivatives were formed by adding $100 \mu \mathrm{L}$ of MSTFA; and bisacylamide derivatives were formed by adding $100 \mu \mathrm{L}$ MBTFA each to the dried extracts from the liquid extraction. Microwave energy was used to assist the derivatisation, and the sample was exposed to $420 \mathrm{~W}$ for a period of $90 \mathrm{~s}$ as per the work by [21], followed by the addition of $1.0 \mathrm{~mL}$ of methanol (MS grade) to alkyl derivatised samples; and $1.0 \mathrm{~mL}$ of iso-octane (MS grade) to acyl and silyl derivatized samples. The derivatised samples were then analyzed by GC/MS.

\subsubsection{Gas Chromatography Mass spectroscopy (GC/MS) analysis}

An Agilent 6890/5973 GC/MS chromatograph with a 30 m Supelco SLB-5ms column, i.d. 250 $\mu \mathrm{m}$, film thickness (df) $0.25 \mu \mathrm{m}$ separation column was used for analysis of MIC water. All injections were performed in split less mode with $1.0 \mu \mathrm{L}$ volume; the oven was held at an initial temperature of $70^{\circ} \mathrm{C}$ for $2.0 \mathrm{~min}$ before increasing to $300{ }^{\circ} \mathrm{C}$ at $10^{\circ} \mathrm{C} \min ^{-1}$; the final temperature was held for 5.0 minutes. The transfer line was held at $280^{\circ} \mathrm{C}$ and the detector voltage at $-1624 \mathrm{~V}$. Mass spectra were acquired from 45 to $650 \mathrm{~m} / \mathrm{z}$, at an acquisition frequency of 4 spectra $\mathrm{s}^{-1}$ [13]. The MS detector was turned off until the excess derivatisation reagent was eluted from the column. This ensures that source filament is not saturated and damaged. 


\section{Results and Discussion}

\subsection{Initial Screening (Spectroscopy)}

It was envisaged that by identifying copper MIC metabolites, a methodology can be developed to predict the likely occurrence of BGW events in critical assets or prevent copper contamination to water supplies. As such, and as per our previous study, it was the intention of the authors to analyse waters believed to be exposed to copper undergoing MIC with no obvious signs of altered colour (e.g., BGW precipitate) [13].

Each water sample was analysed, in triplicate, for free copper and screened by UV-vis spectroscopy and 3DEEM spectroscopy; water samples exposed to bacteria believed to cause MIC were then compared with blank water samples (e.g. a tap water and MilliQ water sample) and a sample exhibiting BGW. UV-vis spectroscopy was used to identify early colour changes in water samples arising from BGW precipitate, while 3DEEM spectroscopy was used to identify 'protein-like' fluorophores (i.e., in the form of concentrated extracellular metabolites). 'Protein-like' fluorophores have been known to be associated with biological activity in natural waters (Hudson et al., 2007).

\subsubsection{UV-Vis spectroscopy}

Analysis of the water samples by UV-Vis spectroscopy (spectra not shown) indicated the presence of unknown compound(s) at $275 \mathrm{~nm}$ and $400 \mathrm{~nm}$ in the samples exposed to bacteria believed to cause MIC; this was also evident in a previous MIC copper study [13]. While the samples appear to be free from BGW percipitate, the presence of the distinct peaks in the UV-Vis spectrum indicate the early stages of MIC of copper.

\subsubsection{DEEM fluorescence spectroscopy}

Analysis of the water samples believed to be exposed to bacteria that causes MIC by 3DEEM spectroscopy highlighted the presence of a unique fluorescent signature (fluorophore at 237/309-321 nm); this signature was not evident in the Milli-Q or tap water procedural blanks (see Figure 1). In addition, the fluorophore in the samples exposed to 
bacteria believed to cause MIC was in agreement with a previous study [13]. This highlights the application of the tool as screening tool for bulk water samples exposed to bacteria that are believed to cause MIC via the presence of 'protein-like' compounds.

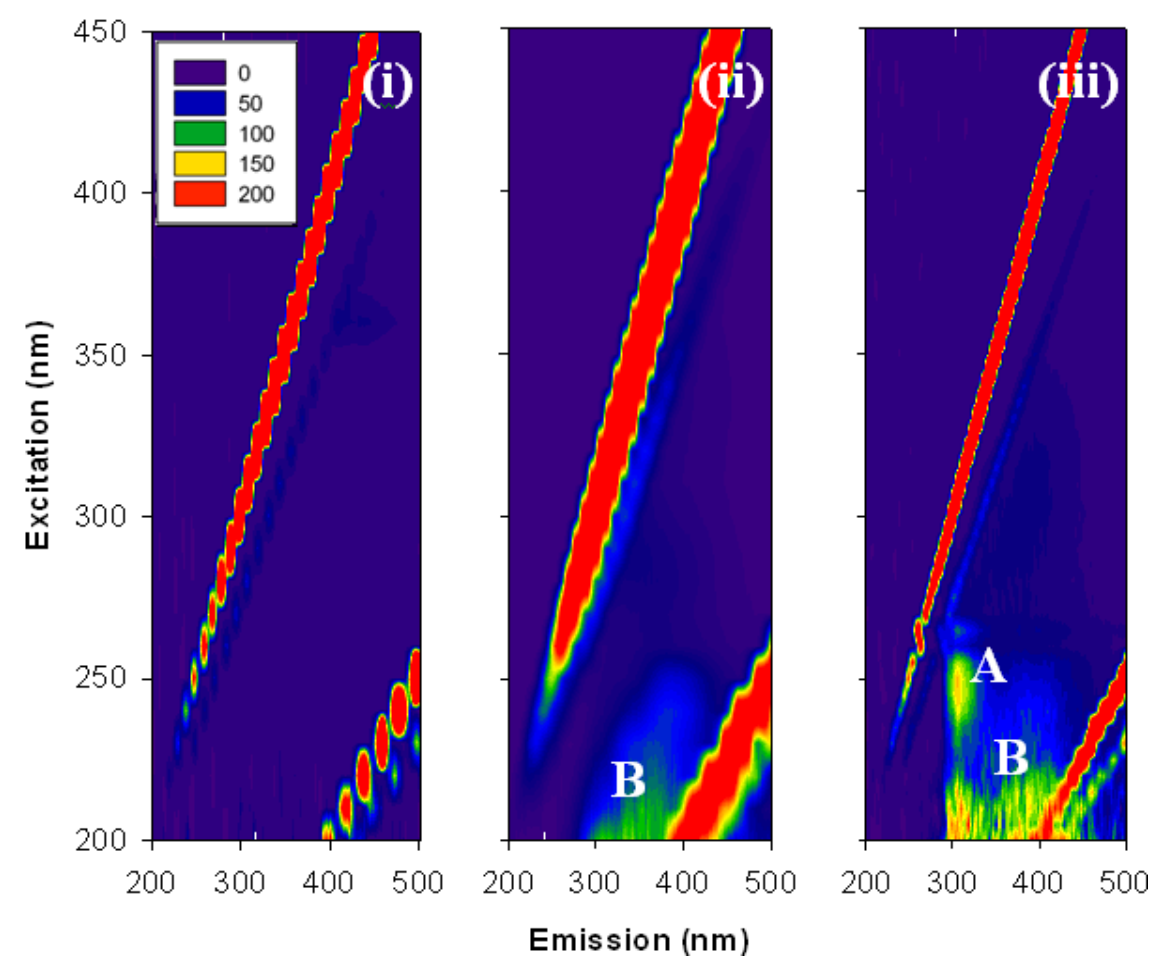

Figure 1: Three dimensional fluorescence spectra of water from pipes exposed to microbial influenced corrosion (MIC).

NOTE: (i) MilliQ water blank (dissolved organic carbon (DOC), $0.1 \mathrm{mg} \mathrm{L}^{-1}$ ). (ii) Tap water blank sample (i.e., tap water sample not suspected of being exposed to copper MIC; DOC $3.1 \mathrm{mg} \mathrm{L}^{-1}$ ). (iii) Tap water sample suspected of being exposed to copper MIC (DOC, $3.5 \mathrm{mg}$ $\left.L^{-1}\right)$. (A) Protein-like fluorophore indicative of the presence of biological activity. (B) Humiclike fluorophore.

\subsubsection{Copper analysis}

Lastly, the water samples and a sample of biofilm were analyzed for free copper by ICPAES. It was found that the majority of the water samples exposed to bacteria believed to cause MIC contained copper at concentrations below the aesthetic and health requirements of the Australian Drinking Water Guidelines (ADWG), which is $2.0 \mathrm{mg} \mathrm{L}^{-1}$ [5]. The analysed copper concentrations typically ranged from 0.43 to $0.86 \mathrm{mg} \mathrm{L}^{-1}$, with exception of two samples that contained BGW precipitate, for which copper occurred at ca. $15-19 \mathrm{mg} \mathrm{L}^{-1}$. In 
contrast, the concentration of copper in the control samples ranged from 0.21 to $0.30 \mathrm{mg} \mathrm{L}^{-1}$; with the tap water blank and MilliQ water $<0.1 \mathrm{mg} \mathrm{L}^{-1}$ as illustrated in Table 1.

The above analysis suggests that the water samples from the trial were from copper exposed to MIC, and the level of free copper in samples with no visible signs of BGW, although relatively high at $0.86 \mathrm{mg} \mathrm{L}^{-1}$ compared to the control, was within the ADWG. However, the two samples exhibiting BGW were observed at levels 9 times the ADWG may occur (noting, the ADWG for Copper is $2.0 \mathrm{mg} \mathrm{L}^{-1}$ ).

\subsection{Confirmation by GC/MS}

\subsubsection{Derivatisation reagent}

The goal of sample derivatisation in GC/MS analysis is to derivatise polar functional groups in the sample into thermally stable, volatile compounds. As such, a series of different derivatisation reagents were applied in order to develop a method that was best suited to metabolomic analysis of water samples from copper pipes that were exposed to bacteria believed to cause MIC. To this end, TMSH was used to derivatise free acids (e.g. fatty acids), phenols and chlorophenols; MSTFA was used to dervatise carboxilic acids, hydroxy and ketocarboxylic acids, amino acids, amines, alcohols, polyalcohols, sugars, and mercaptans; and MBTFA was used as a derivatise alcohols, primary and secondary amine and thiols.

The water samples were derivatised using each derivatisation reagent and analysed in triplicate; common metabolites were observed across all the samples exposed to bacteria believed to cause MIC; these were identified by cross validation with three standard GC/MS reference libraries including Adams, Wiley, and NIST (EPA/NIH), with a minimal probability match of greater than $70 \%$.

In order to assess the effectiveness of the derivatisation reagents, a chemometric analysis was applied to differentiate the samples exposed to bacteria believed to cause MIC and 
those that were not. From the chemometric analysis, the ideal derivatisation reagent can then be selected based on the level of differentiation achieved.

\subsubsection{Chemometric Analysis}

In metabolomics, it is not uncommon for hundreds if not thousands of metabolites to be identified. When a sample consists of so many compounds and/or the sample number is limited, traditional supervised classification algorithms tend to over fit the data. This over fitting is only evident when the classifier is applied on new data [22, 23].

To overcome this problem, principal components analysis (PCA) and partial least squares data analysis (PLS-DA) are applied to the GC/MS spectra $[22,23]$. These are the most common statistical models applied to metabolomic datasets (Lindon et al., 2007). PCA is a data reduction technique used to reduce the dimensionality of a multi-dimensional dataset while retaining the characteristics of the dataset that contribute most to its variance [22]. PLS-DA is a regression extension of PCA that takes advantage of class information in order to maximize the separation between groups of observations. The performance is measured using the sum of squares between peaks over the sum of squares within identified peaks [23].

Figure 2 illustrates the PLS-DA applied to the BGW and tap water samples for each derivatisation reagent used. The classifier was able to discriminate between the samples exposed to bacteria that are known to cause MIC in copper pipes and those that were not. From Figure 2, it is evident that TMSH derivaisation provided the optimal differentiation between the sample set (i.e., the classifier was able to discriminate between the samples and the blanks).

It is interesting to note that two of the BGW samples analysed exhibited a BGW precipitate, this may account for the difference between the samples exposed to bacteria believed to cause MIC as illustrated in Figure 2. However, due to the qualitative nature of the analysis 
described, the BGW samples were classified as a collective group based on the presence or absence of identified metabolites (and substrates). Further research is required to distinguish between the different BGW samples (i.e., those exhibiting BGW precipitate and those that are not) and the concentration of metabolites and substrates expressed. 

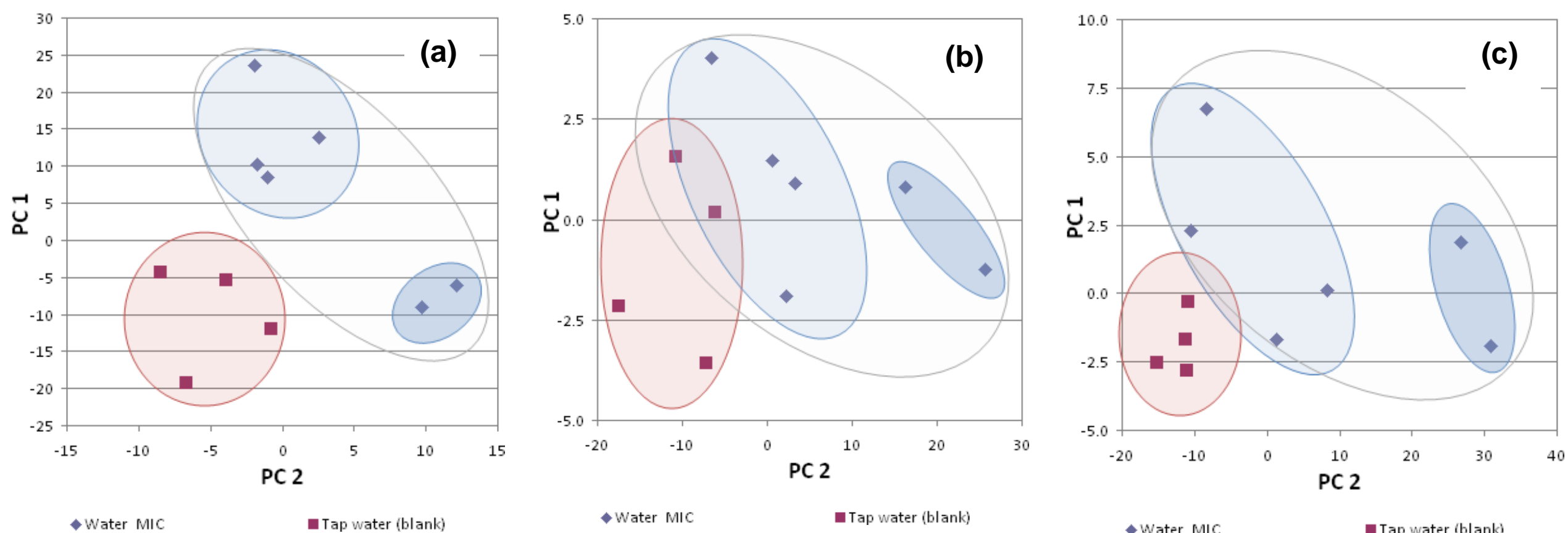

- Water MIC

Tap water (blank)

Figure 2: Partial Least Squares Discrimination Analysis (PLS-DA)

Note: (a) PLS-DA of samples treated with TMSH derivatisation agent; (b) PLS-DA of samples treated with MBTFA derivatisation agent; (c) PLS-DA of samples treated with MSTFA derivatisation agent. $(n=10)$. 


\subsubsection{Copper MIC metabolites}

Utilising TMSH derivatisation, 14 common metabolites were observed in the samples exposed to bacteria that is believed to cause MIC; a sample chromatogram is presented in Figure 3, and the peak identification is shown in Table 2. As illustrated in Table 2, the majority of the metabolites identified are a combination of fatty acids, amino acids and lipids. These are common in biological metabolomic processes, specifically those relating to soluble monomers and sulfur reducing bacteria (SRB) substrates as illustrated by Kaksonen [24]. AS per out previous study, the metabolites were identified via cross validation of four reference libraries with a minimal probability match of $70 \%$ [13].

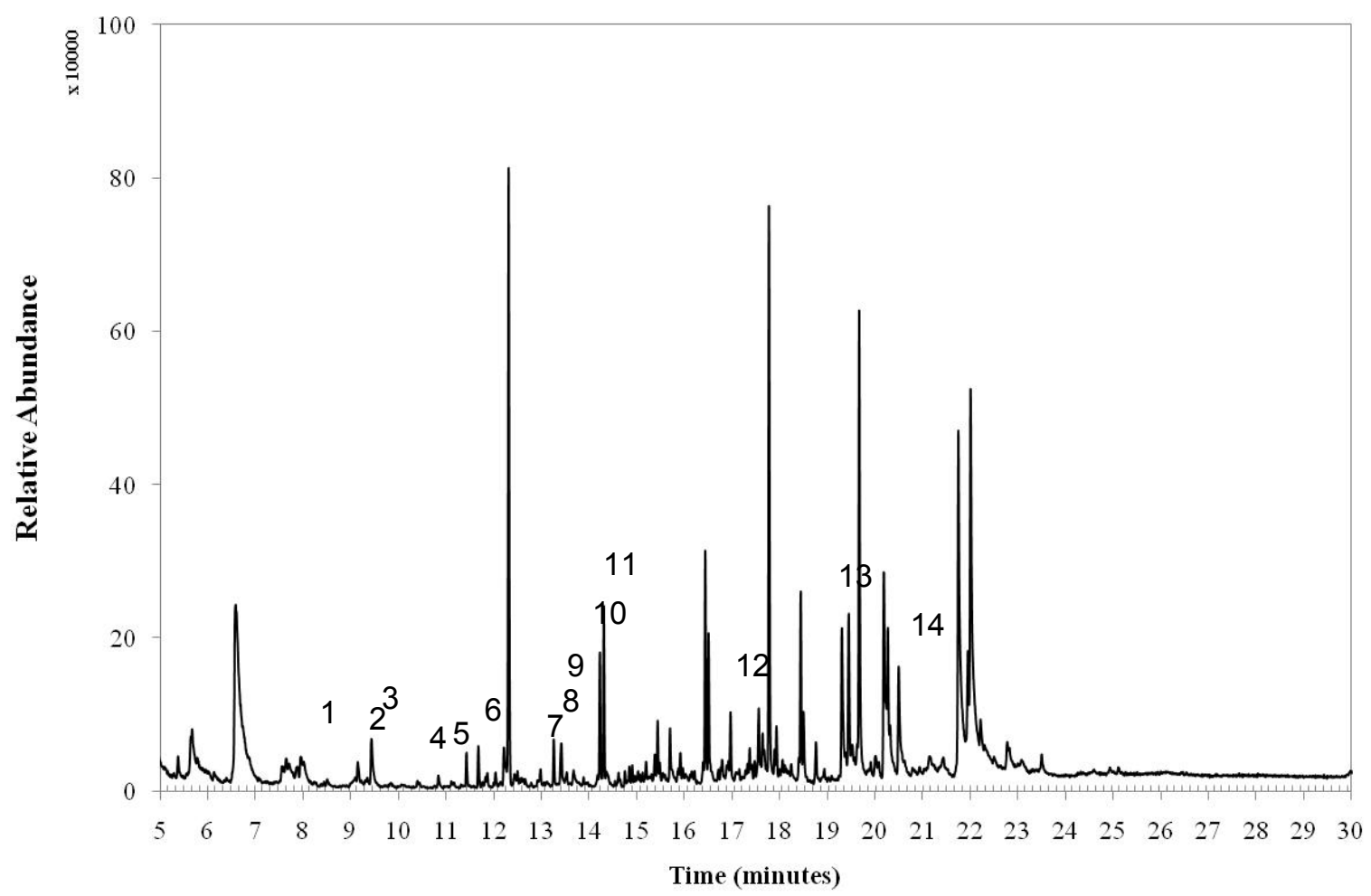

Figure 3: Gas chromatography mass spectrometry (GC/MS) chromatogram of water exposed to bacteria that cause MIC in copper pipes. 
Table 2: Identified common bacterial metabolites found in water samples exposed to bacteria known to cause MIC in copper pipes.

\begin{tabular}{|c|c|c|}
\hline Peak \# & Compound class & Biological function \\
\hline 1 & $\begin{array}{l}\text { Propionic acid } \\
\text { II }_{\text {OH }}\end{array}$ & $\begin{array}{l}\text { A key metabolite in several metabolic pathways; made from } \\
\text { glucose through glycolysis, supplies energy in the citric acid } \\
\text { cycle (Krebs cycle), and can be converted to carbohydrates } \\
\text { via gluconeogenesis, to fatty acids or energy through acetyl- } \\
\text { CoA, to the amino acid alanine and to ethanol }\end{array}$ \\
\hline 2 & Oxalic acid & $\begin{array}{l}\text { Microorganisms produce organic acids like oxalic acid that } \\
\text { solubilise the insoluble phosphorus in tricalcium phosphate, } \\
\text { converting it to soluble phosphate precipitating the calcium } \\
\text { thus making the inorganic phosphorus as phosphate } \\
\text { available }\end{array}$ \\
\hline 3 & $\begin{array}{l}\text { Hexadecanoic acid } \\
\text { (palmitic acid) }\end{array}$ & $\begin{array}{l}\text { The first fatty acid produced during biological fatty acid } \\
\text { synthesis - it contributes to the process of palmitoylation } \\
\text { which is important for membrane localisation of proteins }\end{array}$ \\
\hline 4 & $\begin{array}{l}\text { Glycerol (propan-1,2,3- } \\
\text { triol) }\end{array}$ & $\begin{array}{l}\text { Substructure central to lipids; the most well-known being the } \\
\text { fatty acid esters of glycerol. }\end{array}$ \\
\hline 5 & $\begin{array}{l}\text { Butyric acid (Butanoic } \\
\text { acid or } 1- \\
\text { Propanecarboxylic acid) }\end{array}$ & $\begin{array}{l}\text { Short chain fatty acid occurring in the form of esters in } \\
\text { animal fats and plant oils; a metabolic by-product formed by } \\
\text { selected anaerobic bacteria }\end{array}$ \\
\hline 6 & $\begin{array}{l}\text { Undecanedioic acid acyl- } \\
\text { CoA esters }\end{array}$ & $\begin{array}{l}\text { Fatty acid derivatives may be considered as complex lipids, } \\
\text { and are substrates for a number of important enzymatic } \\
\text { reactions. They play a central role in the regulation of the } \\
\text { metabolism of several enzymes }\end{array}$ \\
\hline 7 & $\begin{array}{l}\text { Nonanoic acid acyl-CoA } \\
\text { esters }\end{array}$ & $\begin{array}{l}\text { Fatty acid derivative which like undecanedioic acid acyl-CoA } \\
\text { esters are substrates for a number of important enzymatic } \\
\text { reactions. They play a central role in the regulation of the } \\
\text { metabolism of several enzymes }\end{array}$ \\
\hline 8 & $\begin{array}{l}\text { L-Tryptophan ( (2S)-2- } \\
\text { amino-3-(1H-indol-3-yl) } \\
\text { propanoic acid) }\end{array}$ & $\begin{array}{l}\text { Amino acid which is commonly synthesised by } \\
\text { microorganisms }\end{array}$ \\
\hline 9 & $\begin{array}{l}\text { Adipic acid (hexane-1,6- } \\
\text { dioic acid) }\end{array}$ & By-product of catalysing glucose \\
\hline 10 & $\begin{array}{l}\text { L-Proline (or Pyrrolidine- } \\
\text { 2-carboxylic acid) }\end{array}$ & $\begin{array}{l}\text { Amino acid which is known to promote the growth of several } \\
\text { species of Enterobacteriaceae }\end{array}$ \\
\hline 11 & $\begin{array}{l}\text { Acetic acid (Ethanoic } \\
\text { acid) }\end{array}$ & $\begin{array}{l}\text { Metabolite of some anaerobic bacteria; sugar is converted to } \\
\text { acetic acid directly without using ethanol as an intermediate. }\end{array}$ \\
\hline 12 & $\begin{array}{l}\text { Maleic acid (or }(Z)- \\
\text { Butenedioic acid) }\end{array}$ & Consumed in the anaerobic metabolism of SRB \\
\hline 13 & $\begin{array}{l}\text { Glutaric acid (or } \\
\text { pentanedioic acid) }\end{array}$ & Consumed in the anaerobic metabolism of SRB \\
\hline 14 & Hexadeconol & $\begin{array}{l}\text { Fatty alcohol (substrate) enzyme that catalyses some } \\
\text { microorganism reactions }\end{array}$ \\
\hline
\end{tabular}

The classifier was able differentiate between the aggregated data sets of the samples exposed to bacteria believed to cause MIC, the samples exhibiting BGW and the sample controls. This differentiation was due to the reduction of carboxylic acids in the samples exposed to bacteria that are believed to cause MIC. This is best illustrated in a hierarchical 
cluster heat map (Figure 4) [25]. The consumption or utilization of substrates, such as carboxylic acids, has been attributed to sulfur reducing bacteria, which are known to contribute to MIC [24].

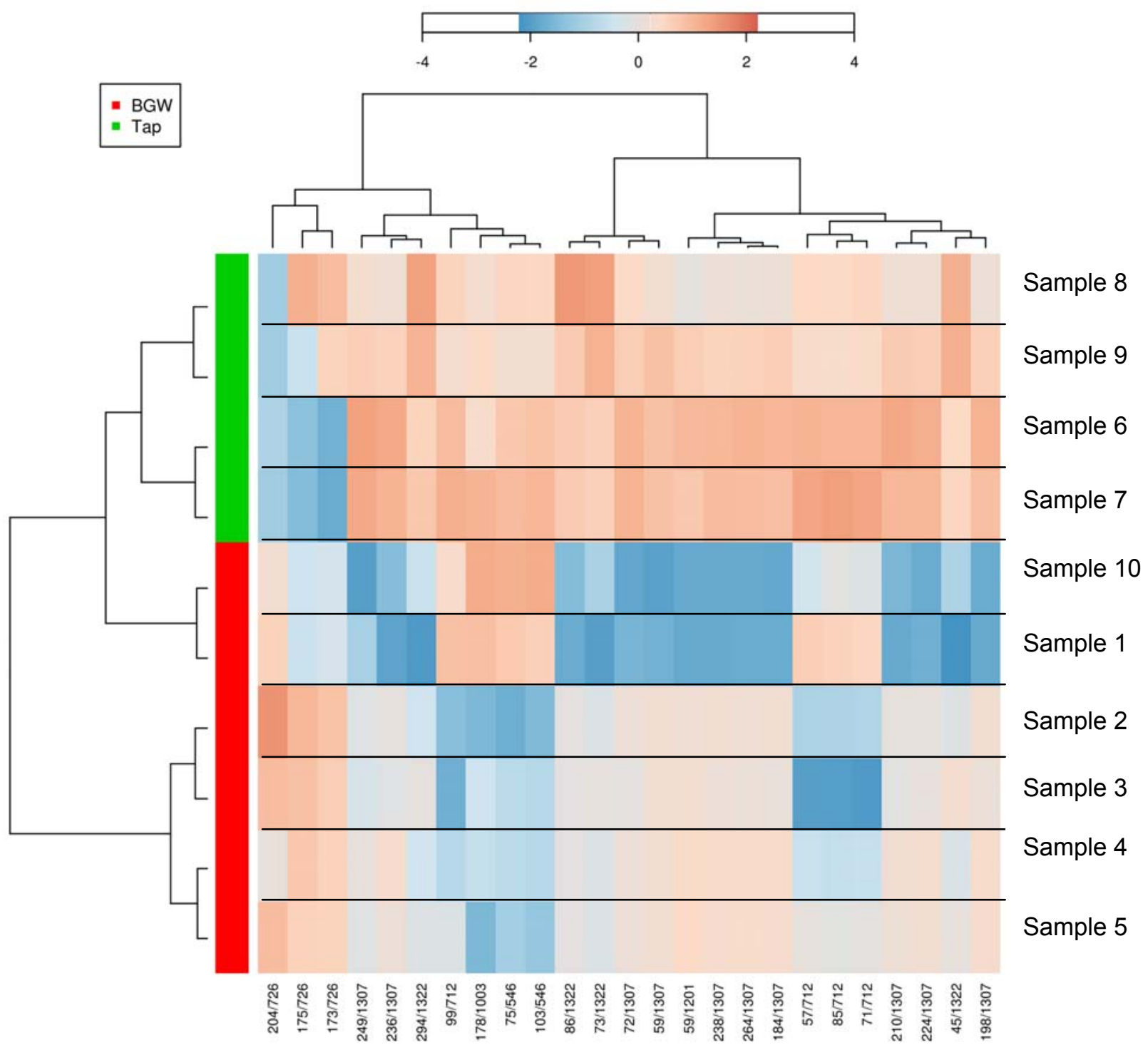

Figure 4: Hierarchical cluster heat map of bulk water samples

Note: The hierarchical cluster heat map comprises the similarity measurement from the PLS$D A$ principal component analysis (top $X$-axis) with a Wards linkage cluster algorithm (left $Y$ axis) to identify key components within the GC-MS spectra that distinguish samples from each other. The bottom $X$-axis illustrates the top 25 MS components/retention times from 6 identified metabolites ( 4 relate to the bacteria believed to cause MIC). The left $Y$-axis demonstrates the correlation of metabolites from the original sample set.

From the heat map, it is evident that there is a significant decrease in glycerol, undecanedioic acid acyl-CoA esters, nonanoic acid acyl-CoA esters and L-tryptophan based on the identified molecular ion and retention times in the samples exposed to bacteria 
believed to cause MIC. It is noteworthy to mention, the metabolites in all the BGW samples suggest the presence of a consortium of anaerobic and aerobic bacteria [24]. The qualitative nature of the experiment did not facilitate the use of metabolite concentration ratios; however, compounds like palmitic acid were observed at lower concentrations. It was evident that the BGW samples had undergone a significant reduction in carboxylic acids in terms of both quantity and type; specifically, some substrates or source compounds observed in the tap water samples were not present in the BGW samples (e.g. pyruvic acid).

It was noted by Lappin-Scott \& Costerton [26] that sulphur-reducing bacteria are categorised by the substrates they consume, those that can use acetate and those that cannot. The absence of fatty acids observed across all of the BGW samples suggests that these samples have an active culture - resulting in the consumption of free fatty acids and while this is believed to influence the deterioration of metal at the biofilm-metal interface within the accelerated corrosion trials, future work is needed to correlate corrosion events with specific metabolites; this is discussed further in the next section.

\section{Discussion}

The research described above has illustrated the application of GC/MS to bulk water samples from copper exposed to bacteria believed to cause corrosion in order to identify the early stages of MIC and to profile MIC metabolites and substrates. While the data presented in this paper was sufficient to distinguish samples within a controlled accelerated corrosion trial, it is anticipated that further research is needed to quantify and link key metabolites arising from biofilms under specific conditions. For example, what are the metabolites expelled and substrates consumed from biofilms at localised corrosion sites under acidic conditions, electrochemical gradients and bacterial compositions. In addition, an investigation of the temporal metabolomic rate is also needed. 
However, it is envisaged that the application is not just limited to copper assets, as a number of researchers have demonstrated MIC processes in a range of materials commonly found in water networks (e.g. iron, steel and polymeric coatings) [27-30]. In addition, it is also important to reiterate the thoughts of Lappin-Scott \& Costerton and Javaherashti $[14,16]$, "biofilms, including those that cause MIC, can be found on any engineered or natural material"; therefore, it could be assumed that the materials used to protect buried infrastructure from corrosion would also be susceptible to biodeterioration, given suitable conditions and enough time. This may lead to MIC attack from both the interior and exterior of pipelines. In fact, Tributsch et al. [31] estimated the annual cost attributed to MIC attack to US industry to be ca. US $\$ 200$ billion dollars; this includes impact imposed on water, gas and fuel infrastructure.

This work has demonstrated that the use of a metabolomics methodology to identify the presence of MIC by measurement of increased biological activity believed to be associated with MIC in copper pipes. The implementation of this methodology is relatively inexpensive with results available within a couple of hours. In contrast, more detailed testing can take much longer and, while providing more expansive data such as the identification of microorganisms, it is believed that the additional information is unnecessary for decision making around asset management. If water practitioners were to monitor the metabolomic profile within the distribution network via regular analysis, they would be able to better manage the associated problems. By comparing waters using a chemometric approach along with the water's metabolomic profile, a library of metabolites and substrates can be created that are linked to observed events or conditions. For example, water flowing through a newly installed pipe will have a different metabolomic profile from water flowing through a pipe that has a mature biofilm, or a pipe experiencing MIC. Therefore, the metabolomic profile can be used as a tool to indicate pipe health (in terms of biofilm). In addition, metabolomic profiling would allow improved water quality by provision of an understanding the degree of disinfection required to ensure sufficiently low microbial levels to meet drinking water guidelines and minimise public health risks. Such a tool will provide early warnings of 
discolouration events such as red water in unlined cast iron pipes and fittings or BGW in copper pipes, as well as taste and odour problems arising from the biofilm development

\section{Conclusions}

The research described above has illustrated the application of GC/MS to water samples obtained from copper exposed to MIC in order to identify the early stages of MIC and to profile MIC metabolites and substrates. In this case, the microbial activity was associated with copper corrosion processes, and the key differentiation between samples exposed to bacteria believed to cause MIC in copper and those not exposed, was the consumption or utilization of carboxylic acids. In addition, it was found that sulfur reducing bacteria, which are known to contribute to MIC, utilized organic acids and other organic compounds as nutrition, during their corrosion influencing reactions on copper.

It is envisaged that this application is not limited to copper structures, as a number of researchers have demonstrated MIC processes in a range of materials. In addition, metabolomic profiling of potable water could enable water practitioners to better manage the relatively large and costly metallic based assets within their water networks through chemometric data analysis. This will result in improved water quality and asset condition by provision of an understanding the degree of disinfection required to ensure sufficiently low microbial levels to meet drinking water guidelines and minimise MIC.

\section{Acknowledgment}

The authors would to thank and acknowledge Ms M. Toifl and Dr R. O'Halloran (CSIRO, Australia) for providing bulk water samples from accelerated copper corrosion trials, and $\mathrm{Mr}$ R. W Wijesuriya (RMIT University) for assisting with the analysis. In addition the authors would like to thank Dr. D. Marney (CSIRO, Australia) and Ensign Laboratories for their continual support of this research. Lastly, the authors would like to thank the Water for a Healthy Country Flagship for its financial support. 


\section{References}

[1] C.D.S. Tuck, C.A. Powell, J. Nuttall, J.A.R. Tony, Corrosion of Copper and its Alloys, in: Shreir's Corrosion, Elsevier, Oxford, 2010, pp. 1937-1973.

[2] I.B. Beech, Corrosion of technical materials in the presence of biofilms--current understanding and state-of-the art methods of study, International Biodeterioration \& Biodegradation, 53 (2004) 177-183.

[3] P.J. Bremer, B.J. Webster, D.B. Wells, Biocorrosion of copper in potable water, Journal American Water Works Association, 93 (2001) 82-91.

[4] G. Bulfin, How to Stop Copper Corrosion and Pinhole Leaks, in: ArticlesBase, ArticlesBase, 2008.

[5] NH\&MRC, Australian Drinking Water Guidelines, in: A. Government (Ed.), 2004.

[6] D. Baum, R. O'Halloran, M. Toifl, Identification and study of copper corrosion biofims and associated bacteria, in: Land \& Water Public Seminar Series, CSIRO, Highett, Australia, 2008.

[7] M. Critchley, R. Taylor, R. O'Halloran, Microbial contribution to blue water corrosion, Materials Performance, 44 (2005) 56-59.

[8] M.M. Critchley, N.J. Cromar, N.C. McClure, H.J. Fallowfield, The influence of the chemical composition of drinking water on cuprosolvency by biofilm bacteria, Journal of Applied Microbiology, 94 (2003) 501-507.

[9] M.M. Critchley, R. Pasetto, R.J. O'Halloran, Microbiological influences in 'blue water' copper corrosion, Journal of Applied Microbiology, 97 (2004) 590-597.

[10] C. Dutkiewicz, H. Fallowfield, Assessment of microbial involvement in the elevation of copper levels in drinking water, Journal of Applied Microbiology, 85 (1998) 597-602.

[11] M. Edwards, S. Jacobs, R.J. Taylor, The blue water phenomenon, Journal American Water Works Association, 92 (2000) 72-82.

[12] K.M.E. Emde, D.W. Smith, R. Facey, Initial investigation of microbially influenced corrosion (MIC) in a low temperature water distribution system, Water Research, 26 (1992) 169-175.

[13] D.J. Beale, M.S. Dunn, D. Marney, Application of GC-MS metabolic profiling to `bluegreen water' from microbial influenced corrosion in copper pipes, Corrosion Science, 52 (2010) 3140-3145.

[14] H.M. Lappin-Scott, J.W. Costerton, Microbial Biofilms, Cambridge University Press, Cambridge, 2003.

[15] P. Sarin, V.L. Snoeyink, J. Bebee, K.K. Jim, M.A. Beckett, W.M. Kriven, J.A. Clement, Iron release from corroded iron pipes in drinking water distribution systems: effect of dissolved oxygen, Water Research, 38 (2004) 1259-1269.

[16] R. Javaherdashti, Microbiologically Influenced Corrosion: An Engineering Insight, Springer, London, UK, 2008. 
[17] J.W.T. Wimpenny, S.L. Kinniment Biochemical reactions and the establishment of gradients within biofilms, Cambridge University Press, Cambridge, 2003.

[18] J.W. Costerton, The Biofilm Primer, Springer, California, 2007.

[19] S.L. Pervcival, J.T. Walker, P.R. Hunter, Microbiological Aspects of Biofilms and Drinking Water, CRC Press, New York, USA, 2000.

[20] G.G. Harrigan, R. Goodacre, Metabolic Profiling: Its role in biomarker discovery and gene function analysis, Kluwer Academic Publishers, Boston, USA, 2003.

[21] K.A. Kouremenos, J.J. Harynuk, W.L. Winniford, P.D. Morrison, P.J. Marriott, One-pot microwave derivatization of target compounds relevant to metabolomics with comprehensive two-dimensional gas chromatography, Journal of Chromatography B, 878 (2010) 1761-1770.

[22] M.J. Adams, Chemometrics in analytical spectroscopy, Cambridge Press, Cambridge, 1995.

[23] S. Bijlsma, I. Bobeldijk, E.R. Verheij, R. Ramaker, S. Kochhar, I.A. Macdonald, B. van Ommen, A.K. Smilde, Large-Scale Human Metabolomics Studies:A Strategy for Data (Pre-) Processing and Validation, Analytical Chemistry, 78 (2005) 567-574.

[24] A. Kaksonen, The performance, kinetics and microbiology of sulfidogenic fluidized-bed reactors treating acidic metal- and sulfatecontaining wastewater., in, Tampere University of Technology, Tampere, Finland, 2004.

[25] S. Bijlsma, I. Bobeldijk, E.R. Verheij, R. Ramaker, S. Kochhar, I.A. Macdonald, B. van Ommen, A.K. Smilde, Large-Scale Human Metabolomics Studies: A Strategy for Data (Pre-) Processing and Validation, Analytical Chemistry, 78 (2005) 567-574.

[26] H. Lappin-Scott, J.W. Costerton, Microbial Biofilms, Cambridge University Press, Cambridge, 2003.

[27] R. Armon, J. Starosvetsky, M. Dancygier, D. Starosvetsky, Adsorption of Flavobacterium breve and Pseudomonas fluorescens p17 on different metals: Electrochemical polarization effect, Biofouling, 17 (2001) 289-301.

[28] E. Ilhan-Sungur, A. Çotuk, Microbial corrosion of galvanized steel in a simulated recirculating cooling tower system, Corrosion Science, 52 (2010) 161-171.

[29] B. Little, P. Wagner, F. Mansfeld, An overview of microbiologically influenced corrosion, Electrochimica Acta, 37 (1992) 2185-2194.

[30] J. Starosvetsky, D. Starosvetsky, R. Armon, Identification of microbiologically influenced corrosion (MIC) in industrial equipment failures, Engineering Failure Analysis, 14 (2007) 1500-1511.

[31] H. Tribtsch, J.A. Rojas-Chapana, C.C. Bartels, A. Ennaoui, W. Hofmann, Role of Transient Iron Sulphide Films in Microbial Corrosion of Steels, Corrosion 53 (1998) 216-227. 